\title{
Development of a new linearizing controller using Lyapunov stability theory and model reference control
}

\author{
Yohan Darcy Mfoumboulou, Mkhululi Elvis Siyanda Mnguni \\ Department of Electrical, Electronic, and Computer Engineering, Cape Peninsula University of Technology, Cape Town, South Africa
}

\begin{tabular}{l}
\hline Article Info \\
\hline Article history: \\
Received Mar 8, 2021 \\
Revised Dec 23, 2021 \\
Accepted Jan 7, 2022 \\
\hline
\end{tabular}

Keywords:

Integral linear quadratic

regulator

Linearization

Lyapunov

Magnetic levitation

Model reference control

Nonlinear

Stability

\begin{abstract}
One of the most challenging aspects in the nonlinear control of a magnetic levitation (Maglev) system is to find an efficient control algorithm to achieve the stability and accuracy of the closed-loop system. The challenge is then to develop a linearizing control algorithm to maintain a steel ball at a desired position. In this paper, a novel linearizing control algorithm is proposed, which consists of the Lyapunov direct method (LDM) and the model reference control (MRC). The Lyapunov function is developed using the nonlinear equations of the magnetic levitation system, and the reference model is a linear second order system. Two control methods are developed to guarantee system robustness and output stability. Firstly, a new integral linear quadratic regulator (ILQR) is designed for the reference model. Then, an additional innovative proportional gain is combined with the linearizing controller to make the nonlinear control signal stronger. The simulation results indicate that the proposed linearizing controller has excellent setpoint tracking, no time delay, fast rising and settling times, and achieves states stability.
\end{abstract}

This is an open access article under the CC BY-SA license.

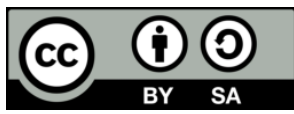

\section{Corresponding Author:}

Yohan Darcy Mfoumboulou

Department of Electrical, Electronic, and Computer Engineering, Cape Peninsula University of Technology Bellville Campus, P.O Box 7530, Cape Town, South Africa

Email: fabolous86yo@yahoo.fr

\section{INTRODUCTION}

Rapid urbanization due to rural exodus has brought a crisis in the transportation sector because a lot more people now make use of transport in the urban environment. Additionally, the environment has been impacted negatively due to the excessive use of fossil fuels in the transportation sector to meet the demands [1]-[4]. The fast depletion of non-renewable resources has highlighted the need for clean, efficient, and sustainable means of transport [4]. The Maglev system has been identified as a solution to the crisis in the transportation sector because it is an electromechanical system, and therefore it does not make use of fossil fuels [5]. The magnetic levitation (Maglev) system is open loop instable and highly nonlinear, which makes it a very challenging control problem [6]-[8]. The efficient control of a Maglev system can reduce the operating cost, fuel economy, driving range and performance in various industries [9], [10]. One of the most efficient methods to stabilize and ensure robustness of the Maglev system is the linearization technique [11][13]. The linearization method draws deductions about the local stability of a nonlinear system around an operating point from the stability characteristics of the system's linear estimation. The stability of dynamic systems can be analyzed in a very precise way with Lyapunov methods if the equivalent mathematical models are expressed as systems of normal differential equations [14], [15]. In the paper, Wong [16], the design of a phase lead compensator to stabilize nonlinear and linearized models of a magnetic levitation system was proposed. The controller showed satisfactory results on both models of the magnetic levitation 
system. But the controller was not robust, which was a major drawback. The linear and nonlinear state-space regulators to control a nonlinear dynamic model of a magnetic levitation system was proposed [17]. The controllers could guarantee the stability of the closed-loop system only in small intervals. In large intervals, the controllers could not bring the system to equilibrium.

Zhang et al. [18], the feedback linearization technique was applied to improve the performance of a magnetic levitation system. Feedback linearization showed better results compared to Taylor linearization technique. A hybrid excitation control algorithm based on Taylor series expansion around an operating point to bring a magnetic levitation system to stability was suggested [19]. This method showed that when the position of the levitation system is far away from its equilibrium point, the controller cannot guarantee the stability of the closed-loop system. Jinquan et al. [20], an adaptive robust regulator to control a nonlinear magnetic levitation train suspension system was designed. The controller showed satisfactory results to variation of parameters, but only if the states of the magnetic levitation system were subjected to constraints. To improve the performance of a hybrid excitation magnetic levitation system, [21] designed a linear controller based on robust feedback linearization method. This method provided a limited degree of robustness because the total mass of the suspension could not be accurately measured. Claudio et al. [22], the study and design of a magnetic levitator system based on electronic components were proposed. The electronic circuit developed provided a certain degree of stability when a triode or triode alternating current (TRIAC) was used to regulate the flow of current in the circuit. A significant drawback of this technique is that it only works for the linearized model of the magnetic levitation system and cannot be applied to its nonlinear model which is the nature of the system. The development of a decoupling control solution to solve the instability of a module suspension system was done [23]. The solution had positive results, but the authors did not consider the actual effects of the track irregularities during real-time operation of the suspension module, which has a significant impact on the nonlinear behavior of the system. A solution to solve the fluctuations of the suspension system when a magnetic levitation system passes at low speed over a track step was proposed [24]. The authors developed a feedback linearization controller based on a decoupling technique. In comparison to a traditional derivative and integral (PID) control algorithm, the decoupling controller reduced the fluctuations by a maximum of $49.6 \%$. Unfortunately, the control solution showed limitations because it cannot be applied to wider operating ranges such as medium and high-speed situations.

This paper proposes a linearizing control algorithm as possible solution to the industrial challenges of achieving accurate control of a nonlinear magnetic levitation system. Lyapunov stability theory based on the model reference control technique is applied to the nonlinear magnetic levitation system. The research gap and merit of the linearizing controller developed in this paper compared to the other controllers reviewed in the literature is that the proposed controller can stabilize all the states of closed-loop system at quicker rate and significantly improve their performances. To guarantee an overshoot below $2 \%$, fast rise time, perfect set-point tracking and robustness of the closed-loop to parameters uncertainties, two innovative approaches are proposed: (a) An additional proportional controller gain is multiplied to the nonlinear controller. This combination of controllers guarantees the robustness of the resulting nonlinear control signal; and (b) A reference model made of the combination of a linear model controlled by an iterative linear quadratic regulator (ILQR) controller is designed. This combination makes the states of the reference model stable to changes of the behavior of the nonlinear model in real-time.

\section{RESEARCH METHOD}

The research design will be explained in two sections, namely, first the theory behind designing a linearizing control algorithm based on the Lyapunov stability theory (subsection 2.1). Then, the steps to design the linearizing controller to stabilize the Maglev system will be provided (subsection 2.2).

\subsection{Theory to design a linearizing control algorithm based on the Lyapunov stability}

The nonlinear magnetic levitation system is characterized by the nonlinear state as (1) and (2) [25]:

$$
\begin{aligned}
& \dot{x}=f(x)+g(x) u \\
& y=C x
\end{aligned}
$$

where $x \in \mathfrak{R}^{n}$ is the state vector (n-vector); $u \in \mathfrak{R}^{m}$ is the control vector; $f \in \mathfrak{R}^{n}$ is the vector valued function; $y \in \mathfrak{R}^{1}$ is the plant output; $C \in \mathfrak{R}^{1 \times n}$ is the output matrix.

The nonlinear model of the magnetic levitation system is used to develop the equation of the linearizing controller. Model reference control (MRC) and Lyapunov second method for stability are used to design a linearizing controller. In the next sections, the steps to develop the controller are described. 


\subsubsection{Reference model}

To properly make the output of the Maglev system accurate, it is necessary to design an ideal reference model system. The idea is to make the error vector between state vector of the reference model and the state vector of the Maglev system go to zero as the time tends to infinity. The design problem is to develop a controller that always produces a signal that forces the state of the magnetic levitation system toward the reference model state [26]-[28]. Figure 1 shows the block diagram of the closed-loop MRC system configuration, where $\mathrm{v}$ is the control input of the reference model.

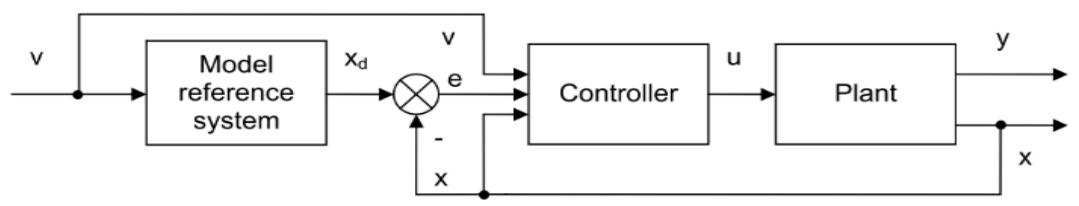

Figure 1. Model-reference control system algorithm

The reference model can be different, linear, or nonlinear, time invariant or time variant, and so on. In this paper, it is assumed that the reference model is linear and described by (3):

$$
\begin{aligned}
& \dot{x}_{d}=A x_{d}+B v \\
& y=C x_{d}
\end{aligned}
$$

where $x_{d} \in \Re^{n}$ is the state vector of the model; $v \in \Re^{m}$ is the control vector for the reference model; $A \in$ $\Re^{n \times n}$ is the constant state matrix; $B \in \Re^{n \times m}$ is the constant control matrix and $C \in \mathfrak{R}^{1 \times n}$ is the constant output matrix. It is assumed that the eigenvalues of $A$ have negative real parts so that the model-reference system has an asymptotically stable state of equilibrium. The control input $v$ can be selected in such a way that $x_{d}$ follows some desired trajectory, which then will be followed by the nonlinear magnetic levitation system. The error vector $\boldsymbol{\varepsilon}$ is defined by (4):

$$
\varepsilon=x_{d}-x
$$

where $\varepsilon \in \Re^{n}, x$ is the actual state of the plant. The requirements towards the closed-loop systems are that the error $\varepsilon$ must be reduced to zero by a suitable control vector $u$. To include the model equation and the plant equation in the error (4) it is necessary to differentiate the error (4) according to the time:

$$
\begin{aligned}
\dot{\varepsilon} & =\dot{x}_{d}-\dot{x}=A x_{d}+B v-f(x)-g(x) u \\
& =A x_{d}-A x+A x+B v-f(x)-g(x) u \\
& =A\left(x_{d}-x\right)+A x+B v-f(x)-g(x) u
\end{aligned}
$$

$\therefore \varepsilon=x_{d}-\boldsymbol{x}$, then the above equation can be simplified as (5).

$$
\dot{\varepsilon}=A \varepsilon+A x+B v-f(x)-g(x) u
$$

The (5) is a differential equation for the error vector. Then a linearizing controller can be designed such that at steady state $x=x_{d}$ and $\dot{x}=\dot{x}_{d}$, or $\varepsilon=\dot{\varepsilon}=0$. Thus, the equilibrium $\varepsilon=0$ will be the origin of the coordinate system.

\subsubsection{Linearizing controller}

Based on the understanding of the Lyapunov direct method, the positive definite Lyapunov function $V$ for the system is constructed and its time derivative $\dot{V}$ is examined. If $\dot{V}$ is negative definite, that means that the energy contained in the system is continuously dissipating. The system is moving towards the stable equilibrium. The following sub-steps present the procedures of how the linearizing controller design is based on the Lyapunov direct method. 
Step 1: Construction of a Lyapunov function for the system and determination of its first derivative. An ideal point to start the design of the control vector $u$ is to construct a Lyapunov function system. In this paper, the Lyapunov function is assumed to be in quadratic form (6).

$$
V(\varepsilon)=\varepsilon^{T}
$$

where $P \in \mathfrak{R}^{n \times n}$ is a positive-definite Hermitian or real symmetric matrix. Because the function $V(\varepsilon)$ is in quadratic form and the matrix $P$ is positive definite, it is true that $V(\varepsilon)$ is positive definite.

Differentiating the positive definite function $V(\varepsilon)$ along the system trajectory, its time derivative is obtained as:

$$
\begin{aligned}
\dot{V}(\varepsilon)= & \dot{\varepsilon}^{T} P \varepsilon+\varepsilon^{T} P \dot{\varepsilon} \\
= & {[A \varepsilon+A x+B v-f(x)-g(x) u]^{T} P \varepsilon+\varepsilon^{T} P[A \varepsilon+A x+B v-f(x)-g(x) u] } \\
= & {\left[A^{T} \varepsilon^{T}+A^{T} x^{T}+B^{T} v^{T}-f^{T}(x)-g^{T}(x) u^{T}\right] P \varepsilon+\varepsilon^{T} P[A \varepsilon+A x+B v-f(x)-g(x) u] } \\
= & A^{T} \varepsilon^{T} P \varepsilon+A^{T} x^{T} P \varepsilon+B^{T} v^{T} P \varepsilon-f^{T}(x) P \varepsilon-g^{T}(x) u^{T} P \varepsilon+\varepsilon^{T} P A \varepsilon+\varepsilon^{T} P A x+\varepsilon^{T} P B v \\
& -\varepsilon^{T} P f(x)-\varepsilon^{T} P g(x) u \\
\dot{V}(\varepsilon)= & \varepsilon^{T}\left[A^{T} P+P A\right] \varepsilon+2 N
\end{aligned}
$$

where:

$$
\begin{aligned}
2 N & =A^{T} x^{T} P \varepsilon+\varepsilon^{T} P A x-f^{T}(x) P \varepsilon-g^{T}(x) u^{T} P \varepsilon-\varepsilon^{T} P f(x)-\varepsilon^{T} P g(x) u+B^{T} v^{T} P \varepsilon+\varepsilon^{T} P B v \\
& =\varepsilon^{T} P A x+\varepsilon^{T} P A x-\varepsilon^{T} P f(x)-\varepsilon^{T} P g(x) u-\varepsilon^{T} P f(x)-\varepsilon^{T} P g(x) u+\varepsilon^{T} P B v+\varepsilon^{T} P B v \\
2 N & =2 \varepsilon^{T} P[A x-f(x)-g(x) u+B v]
\end{aligned}
$$

since $P$ is a symmetrical matrix and $P^{T}=P$ :

$$
N=\varepsilon^{T} P[A x-f(x)-g(x) u+B v]
$$

$N$ is a scalar quantity.

Step 2: Calculation of the linearizing control algorithm. $V(\varepsilon)$ is assumed to be a Lyapunov function, if its first derivative is negative definite then the system expressed in (7) is stable. The first derivative of $V(\varepsilon)$ is the sum of two expressions:

$$
\dot{V}(\varepsilon)=\varepsilon^{T}\left[A^{T} P+P A\right] \varepsilon+2 N
$$

for $\dot{V}(\varepsilon)$ to be negative definite, the two terms of (10) must be negative definite:

$$
\varepsilon^{T}\left[A^{T} P+P A\right] \varepsilon<0 \text { or } A^{T} P+P A=-Q
$$

where $Q$ is a positive definite matrix and $\dot{V}(\varepsilon)=\varepsilon^{T}\left[A^{T} P+P A\right] \varepsilon+2 N$ (first condition).

$$
N \leq 0 \text { (Second condition). }
$$

Based on (9) and (10), it can be concluded that $N$ can be made negative or equal to zero through suitable selection of the plant control vector $u$ which is part of the first derivative of the Lyapunov function $\dot{V}(\varepsilon)$. Then from noting that $V(\varepsilon) \rightarrow \infty$ as $\|\varepsilon\| \rightarrow \infty$, the equilibrium state $\varepsilon=0$ is asymptotically stable in the larger range. The fulfilment of condition (1) can be achieved by an ideal choice of the matrix $P$ since the eigenvalues of the state matrix $A$ are selected to be with negative real parts. The problem to solve now is to select an appropriate vector $u$ so that $N$ is either zero, or negative scalar quantity. The determination of the linearizing controller $u$ can be done with proper selected values of the matrix $P$ or the matrix $Q$. The obtained linearizing controller $u$ makes the system stable and follows the desired trajectory determined by the reference model.

\subsection{Design of a lyapunov-based and MRC-based linearizing controller for the magnetic levitation system}

Based on the study and understanding of the MRC theory, the Lyapunov stability theory, the Lyapunov direct method and the LQR control method, the following sub-sections cover explicitly the design of the linearizing controller to stabilize the nonlinear magnetic levitation system. 


\subsubsection{The nonlinear model of the magnetic levitation system}

Figure 2 shows the schematic diagram of the magnetic levitation system developed by [16]. The magnetic levitation system is an electro-mechanical system made of the following components: an electromagnet, a current controller, a sensor, photo-emitters, a photo-receiver, and a steel ball. The goal of the system is to control the position of the steel ball by regulating the current in the electromagnet through the input voltage. The dynamic of the system is derived based on the first principles of basic electrical and mechanical laws.

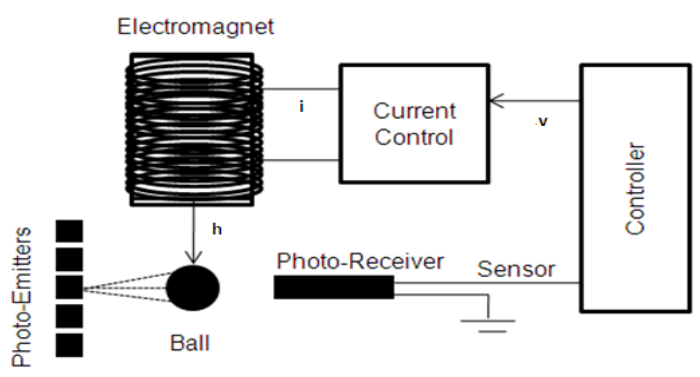

Figure 2. Magnetic levitation system [16]

The nonlinear reduced order of the magnetic levitation system described in Figure 2 is selected for the investigation [29]. This reduced order model is defined as:

$$
\begin{aligned}
& {\left[\begin{array}{l}
\dot{x}_{1} \\
\dot{x}_{2}
\end{array}\right]=\left[\begin{array}{c}
x_{2} \\
-g-\frac{c}{m} x_{2}
\end{array}\right]+\left[\begin{array}{c}
0 \\
\frac{1}{m a\left(x_{1}+b\right)^{4}}
\end{array}\right] u, x(0)=x_{0}} \\
& y=C x
\end{aligned}
$$

the states of the nonlinear magnetic levitation system are defined as:

$$
\begin{aligned}
& x_{1}=\text { ball position } \\
& x_{2}=\text { velocity of the ball }
\end{aligned}
$$

where: $C=\left[\begin{array}{ll}1 & 0\end{array}\right] ; a, b$ and $c$ are constants related with the magnetic coil properties. The values of the parameters of the process are:

$$
\begin{aligned}
& g=9.81 \mathrm{~N} / \mathrm{Kg} \\
& m=0.12 \mathrm{Kg} \\
& a=0.95 \\
& b=6.28 \\
& c=0.15 \mathrm{~N} / \mathrm{Kg}
\end{aligned}
$$

the nonlinear model represented in (11) and (12) can be rewritten in the common form as (15).

$$
\begin{aligned}
& \dot{x}=f(x)+g(x) u \\
& y=C x
\end{aligned}
$$

Figure 3 shows the behaviour of the nonlinear reduced order model of the magnetic levitation system. The simulation is done with the following parameters:

- Initial conditions: [0.05m 0]'

- Step input: 0.3[volts]

The position state response of the nonlinear model of the magnetic levitation system shows that under step continuous force, the ball position moves toward infinity as the time goes. This analysis confirms that the magnetic ball levitation is a nonlinear open loop unstable system that needs to be controlled efficiently. 


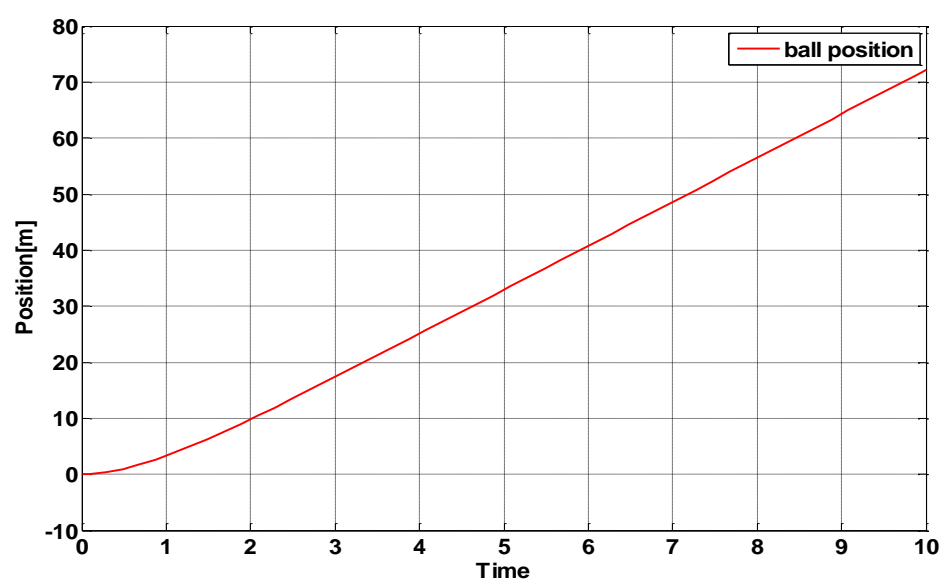

Figure 3. Open loop response of the nonlinear model of magnetic levitation system when the step input is at 0.3 volts

\subsubsection{Model of the desired linear system (reference model)}

The linear reference model can be written in the following form:

$$
\begin{aligned}
& \dot{x}_{d}=A x_{d}+B v, x_{d}(0)=x_{d 0} \\
& y_{d}=C x
\end{aligned}
$$

where $x_{d} \in \mathfrak{R}^{2}$ is the desired state space vector, $v \in \mathfrak{R}^{1}$ is the control vector for the reference model, $A \in$ $\mathfrak{R}^{2 \times 2}$ and $B \in \mathfrak{R}^{2 \times 1}$ are the state and control matrices of the reference model in the state-space form, $x_{d 0}$ is the initial state. The model of the magnetic levitation is of second order. Therefore, the desired model is selected to be of second order too. The eigenvalues of the state matrix $A_{d}$ are selected to be with negative real parts to ensure stability of the reference model.

\subsubsection{Determination of the error between the reference model and the maglev states}

The error between the reference model and the nonlinear model of the magnetic levitation system is (18).

$$
\varepsilon=x_{d}-x, \varepsilon \in \mathfrak{R}^{2 \times 2}
$$

The error signal $\boldsymbol{\varepsilon}$ must be reduced to zero by a suitable control vector $\boldsymbol{u}$. The differential equation of the error is (9).

$$
\begin{aligned}
\dot{\varepsilon} & =\dot{x}_{d}-\dot{x}=A x_{d}+B v-f(x)-g(x) u \\
& =A x_{d}+A x-A x+B v-f(x)-g(x) u \\
& =A\left[x_{d}-x\right]+A x+B v-f(x)-g(x) u \\
& =A \varepsilon+A x+B v-f(x)-g(x) u
\end{aligned}
$$

The problem is to design a control vector $u$, such that at the equilibrium state $x=x_{d}, \dot{x}=\dot{x}_{d}, \varepsilon=\dot{\varepsilon}=0$ is achieved.

- Design of of the linearizing controller

Step 1: Construction of Lyapunov function

The construction of the Lyapunov function for the error differential shown in (18) is:

$$
V(\varepsilon)=\varepsilon^{T} P \varepsilon
$$

Where $P$ is a symmetrical positive definite matrix, $P \in \mathfrak{R}^{2 \times 2}$.

Step 2: Calculation of the first derivative of the Lyapunov function

The calculation of the first derivative of the Lyapunov function is the following:

$$
\begin{aligned}
& \dot{V}(\varepsilon)=\dot{\varepsilon}^{T} P \varepsilon+\varepsilon^{T} P \dot{\varepsilon} \\
& =[A \varepsilon+A x+B v-f(x)-g(x) u]^{T} P \varepsilon+\varepsilon^{T} P[A \varepsilon+A x+B v-f(x)-g(x) u]
\end{aligned}
$$




$$
\begin{aligned}
= & {\left[A^{T} \varepsilon^{T}+A^{T} x^{T}+B^{T} v^{T}-f^{T}(x)-g^{T}(x) u^{T}\right] P \varepsilon+\varepsilon^{T} P[A \varepsilon+A x+B v-f(x)-g(x) u] } \\
= & A^{T} \varepsilon^{T} P \varepsilon+A^{T} x^{T} P \varepsilon+B^{T} v^{T} P \varepsilon-f^{T}(x) P \varepsilon-g^{T}(x) u^{T} P \varepsilon+\varepsilon^{T} P A \varepsilon+\varepsilon^{T} P A x+\varepsilon^{T} P B v-\varepsilon^{T} P f(x) \\
& \quad-\varepsilon^{T} P g(x) u \\
= & \varepsilon^{T}\left[A^{T} P+P A\right] \varepsilon+2 \varepsilon^{T} P[A x+B v-f(x)-g(x) u] \\
= & -\varepsilon^{T} Q \varepsilon+2 N \\
Q= & A^{T} P+P A
\end{aligned}
$$

where the matrix $Q$ is symmetrical and positive definite.

$$
N=\varepsilon^{T} P[A x+B v-f(x)-g(x) u]
$$

The derived (21) is the expression of the first derivative of the Lyapunov function. To make the error in the closed loop system to go to zero as time goes to infinity $(t \rightarrow \infty)$, it is fundamental for this equation to be negative definite. The first expression of this equation is negative definite as $Q$ is selected to be positive definite. Then the second expression $N$ can be made zero or negative $N \leq 0$ by a convenient selection of the control $u$.

Step 3: Calculation of the linearizing controller for $N$ :

The calculation of the linearizing controller $\boldsymbol{u}$ is done by some transformations of the expression

$$
\begin{aligned}
& N=\varepsilon^{T} P[A x+B v-f(x)-g(x) u] \leq 0 \\
& N=\varepsilon^{T} P[A x+B v-f(x)]-\varepsilon^{T} P[g(x) u] \leq 0 \\
& \varepsilon^{T} P[A x+B v-f(x)] \leq \varepsilon^{T} P[g(x) u]
\end{aligned}
$$

The expressions from both sides of the equation are scalars, which depend on time. That is the reason why it is possible to divide both sides by $\boldsymbol{\varepsilon}^{T} \boldsymbol{P}[\boldsymbol{g}(\boldsymbol{x})]$ and obtain:

$$
u \geq \frac{\varepsilon^{T} P[A x+B v-f(x)]}{\varepsilon^{T} P[g(x)]}
$$

Step 4: Representation of the diagram of the closed-loop system

Based on (23), a diagram of the closed loop system can be drawn. The expression of the linearizing controller is multiplied by a new proportional gain $\boldsymbol{I}>\mathbf{0}$ to make the realization in the (23) stronger. The nonlinear controller developed makes the first derivative of the Lyapunov function negative. Then, it linearizes the closed loop system consisting of the linearizing controller and the magnetic levitation system. This combination makes the behaviour of the closed-loop system follow the behaviour of the reference model. The block diagram of the closed loop system is shown in Figure 4.

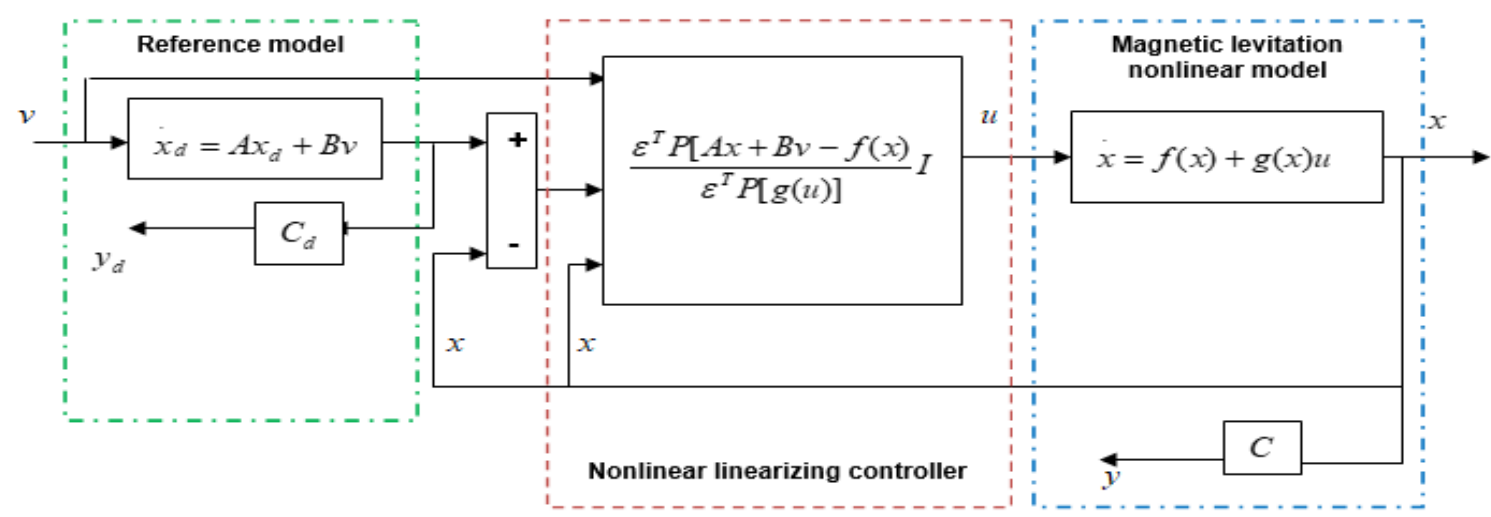

Figure 4. Block diagram of the closed loop system 


\subsubsection{Design of a linear control for the linearized closed-loop system}

Figure 4 shows that the desired vector $\boldsymbol{x}_{\boldsymbol{d}}$ depends on the input control vector $\boldsymbol{v}$ for the reference model. Different values of $\boldsymbol{v}$ will give different values of $\boldsymbol{x}_{\boldsymbol{d}}$. From the expression of the nonlinear control given by (23), the values of $\boldsymbol{u}$ depend on the parameters of the nonlinear magnetic levitation model. The implementation of the linearizing controller then cannot be very successful because of the influence of the disturbances, and the changes of the plant parameters. The linearizing and stabilizing effects could be lost and could make the system unstable. This means that an additional innovative Integral Linear Quadratic Regulator (ILQR) controller must be designed to make the closed loop system more robust and its output exactly to follow the desired behaviour of the reference model.

Step 1: Specification of the closed-loop system with the reference model and for the linearized closed-loop system

Let assume that the desired output of the entire closed loop system is a set point value $\boldsymbol{y}^{\boldsymbol{s} \boldsymbol{p}}$. Because of this assumption, it is crucial to determine the optimal control law such that: $\boldsymbol{y}=\boldsymbol{y}^{\boldsymbol{s p}}$ or $\boldsymbol{\varepsilon}=\boldsymbol{y}^{\boldsymbol{s p}}-\boldsymbol{y}$ when $\boldsymbol{t} \rightarrow \infty$.

Step 2: Design of the linear quadratic controller

The expression of the error signal between the set-point and the output of the plant is defined as:

$$
\dot{\varepsilon}_{d}=A \varepsilon_{d}+B v, \varepsilon_{d 0}=y^{s p}-C x_{d 0}
$$

the aim is to design a linear integral quadratic controller to make the error between the set-point and the current value of the system output to go to zero. Then the extended version of the model is built as (24).

$$
\begin{aligned}
& \dot{x}_{d}=A_{d} x_{d}+B v \\
& \dot{x}_{n+1}=y^{s p}-y_{d}, x_{d}(0)=x_{d 0} \\
& y_{d}=C x_{d}
\end{aligned}
$$

It is necessary to design the linear integral quadratic controller in the state-space form:

$$
v=\bar{H}_{\varnothing} \bar{x}_{d}=H x_{d}+H_{n+1} x_{n+1}, \bar{H}_{\emptyset} \in \mathfrak{R}^{m \times(n+1)}
$$

where: $\overline{\dot{x}}_{d}=\bar{A} \bar{x}_{d}+\bar{B} v+\left[\begin{array}{c}0_{2 \times 1} \\ 1\end{array}\right] y^{s p}$

$$
\bar{A}=\left[\begin{array}{cc}
A_{d} & 0 \\
-C_{d} & 0
\end{array}\right], \bar{B}=\left[\begin{array}{c}
B_{d} \\
0
\end{array}\right], \bar{H}=\left[\begin{array}{ll}
H & H_{1}
\end{array}\right]
$$

The fundamental idea of (24) and (25) is that the servo problem is converted to a problem for design of a linear quadratic regulator in which the set-point is zero. The problem to find the matrix controller $\overline{\boldsymbol{H}}$ can be (27):

$$
J_{p}=\int_{0}^{\infty}\left[\left\|\bar{x}_{d}\right\|^{2} \bar{Q}+\|v\|^{2} \bar{R}\right] d t, \bar{Q} \in \mathfrak{R}^{(n+1) \times(n+1)}, \bar{R} \in \mathfrak{R}^{m \times m}
$$

where: $\overline{\boldsymbol{R}}>\mathbf{0}$ and $\overline{\boldsymbol{Q}} \geq \mathbf{0}$ are weighting matrices [30], [31]. Equation (27) is minimized under the model (24) Step 3: Solution of the linear quadratic regulator problem

The resolution of linear quadratic regulator problem is given by (28).

$$
v=-\bar{H}_{\emptyset} \bar{x}_{d}=-\bar{H} x_{d}+H_{1} \varepsilon=-\bar{R}^{-1} \bar{B}^{T} \bar{P} \bar{x}_{d}
$$

In (28), $\overline{\boldsymbol{P}}$ is the solution of the Riccati as:

$$
\bar{H}_{\emptyset}=\left[\begin{array}{ll}
H & H_{1}
\end{array}\right] \in \mathfrak{R}^{1 \times 2}
$$

the solution of the problem can be found in MATLAB using the ' $l q r$ ' function, its structure is as follow:

$$
\left[\bar{H}_{\emptyset}, \quad \bar{P}, \quad E\right]=\operatorname{lqr}(\bar{A}, \bar{B}, \bar{Q}, \bar{R})
$$

$\overline{\boldsymbol{H}}_{\emptyset}$ is the matrix of the regulator; $\overline{\boldsymbol{P}}$ is the matrix of the Riccati equation and $\boldsymbol{E}$ is the vector of the poles of the closed-loop matrix $\left[\overline{\boldsymbol{A}}-\overline{\boldsymbol{B}} \overline{\boldsymbol{H}}_{\varnothing}\right]$. To make the system stable, all the poles must be with real negative parts. 
The control $v$ is obtained as (29).

$v=-H x_{d}+H_{1} \varepsilon$

The augmented matrices with the additional integrator states can be expressed as:

$$
\begin{aligned}
& \bar{A}=\left[\begin{array}{cc}
A_{d} & 0 \\
-C_{d} & 0
\end{array}\right]=\left[\begin{array}{ccc}
0 & 1 & 0 \\
-2 & -3 & 0 \\
-1 & 0 & 0
\end{array}\right] ; \\
& \bar{B}=\left[\begin{array}{c}
B_{d} \\
0
\end{array}\right]=\left[\begin{array}{l}
0 \\
1 \\
0
\end{array}\right]
\end{aligned}
$$

where:

$$
\bar{A}=\left[\begin{array}{ll}
A_{d} \in \Re^{2 \times 2} & 0 \in \mathfrak{R}^{2 \times 1} \\
C_{d} \in \Re^{1 \times 2} & 0 \in \mathfrak{R}^{1 \times 1}
\end{array}\right] ; \text { and } \bar{B}=\left[\begin{array}{c}
B \in \mathfrak{R}^{2 \times 1} \\
0 \notin \mathfrak{R}^{1 \times 1}
\end{array}\right]
$$

The values of the weighting matrices $\overline{\boldsymbol{Q}}$ and $\overline{\boldsymbol{R}}$ are summarized in Table 1 .

Table 1 also shows the different values of $\overline{\boldsymbol{H}}$ at different set points.

Step 4: Application of the linear integral controller to the closed-loop system with the linearizing controller and the reference model

The structure of the block diagram with the linearizing MRC based on Lyapunov second method is shown in Figure 5. For the implementation of the linear controller in the closed-loop system, it is important that the feedback is not taken from the output of the reference model but from the output of the nonlinear model of the magnetic levitation process. Using the process real output will lead to better results as the

\begin{tabular}{|c|c|c|c|c|c|c|c|c|}
\hline Set points & Initial conditions & \multicolumn{3}{|c|}{$\begin{array}{c}\text { Matrix } \\
\overline{\mathbf{Q}}\end{array}$} & $\underset{\overline{\boldsymbol{R}}}{\text { Matrix }}$ & \multicolumn{3}{|c|}{$\begin{array}{l}\text { Feedback controller gain } \\
\qquad \overline{\boldsymbol{H}}\end{array}$} \\
\hline $0.01 \mathrm{~m}$ & {$\left[\begin{array}{lll}0.05 & 0 & 0\end{array}\right]^{\prime}$} & {$\left[\begin{array}{c}91000 \\
0\end{array}\right.$} & $\begin{array}{c}0 \\
300\end{array}$ & $\left.\begin{array}{l}0 \\
0\end{array}\right]$ & 0.1 & {$[952.67$} & 67.1 & $-10]$ \\
\hline $0.09 \mathrm{~m}$ & {$\left[\begin{array}{lll}0.05 & 0 & 0\end{array}\right]^{\prime}$} & {$\left[\begin{array}{c}0 \\
69000 \\
0 \\
0\end{array}\right.$} & $\begin{array}{c}0 \\
0 \\
750 \\
0 \\
\end{array}$ & $\begin{array}{c}10 \\
0 \\
0 \\
25\end{array}$ & 1 & [261.37 & 31.8 & $-5]$ \\
\hline
\end{tabular}
integral LQR controller compensates for disturbances over the real process.

Table 1. Parameters obtained for the ILQR

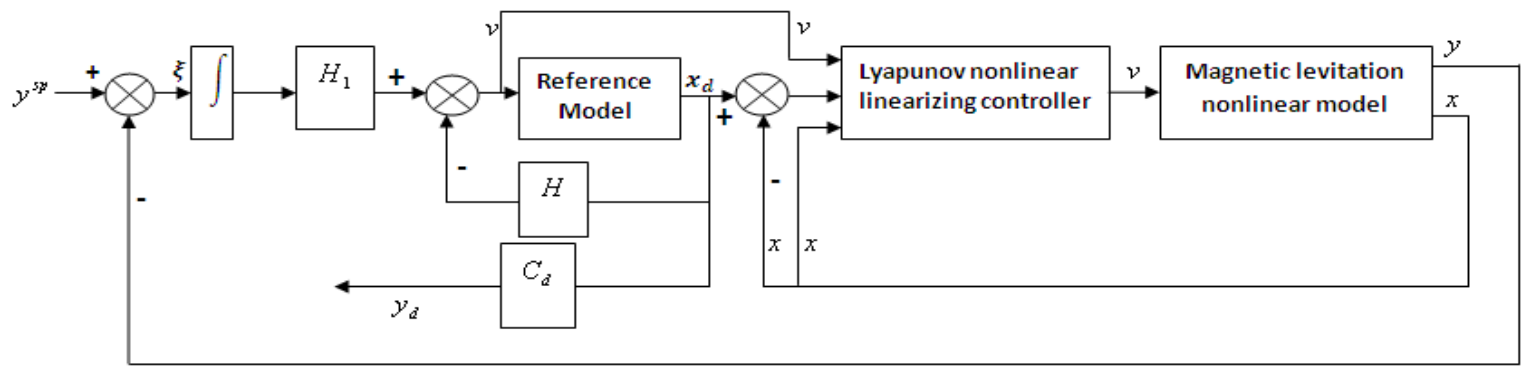

Figure 5. Block diagram of the Lyapunov stability based on model reference control system

\section{SIMULATION RESULTS AND ANALYSIS}

The simulation is done in MATLAB/Simulink environment. The closed-loop diagram based on Lyapunov direct method is shown in Figure 6. This closed loop diagram comprises four important subsystems:

- $\quad$ Reference model (Figure 7)

- Integral LQR controller (Figure 8)

- Magnetic levitation nonlinear model (Figure 9)

- Linearizing controller (Figure 10) 


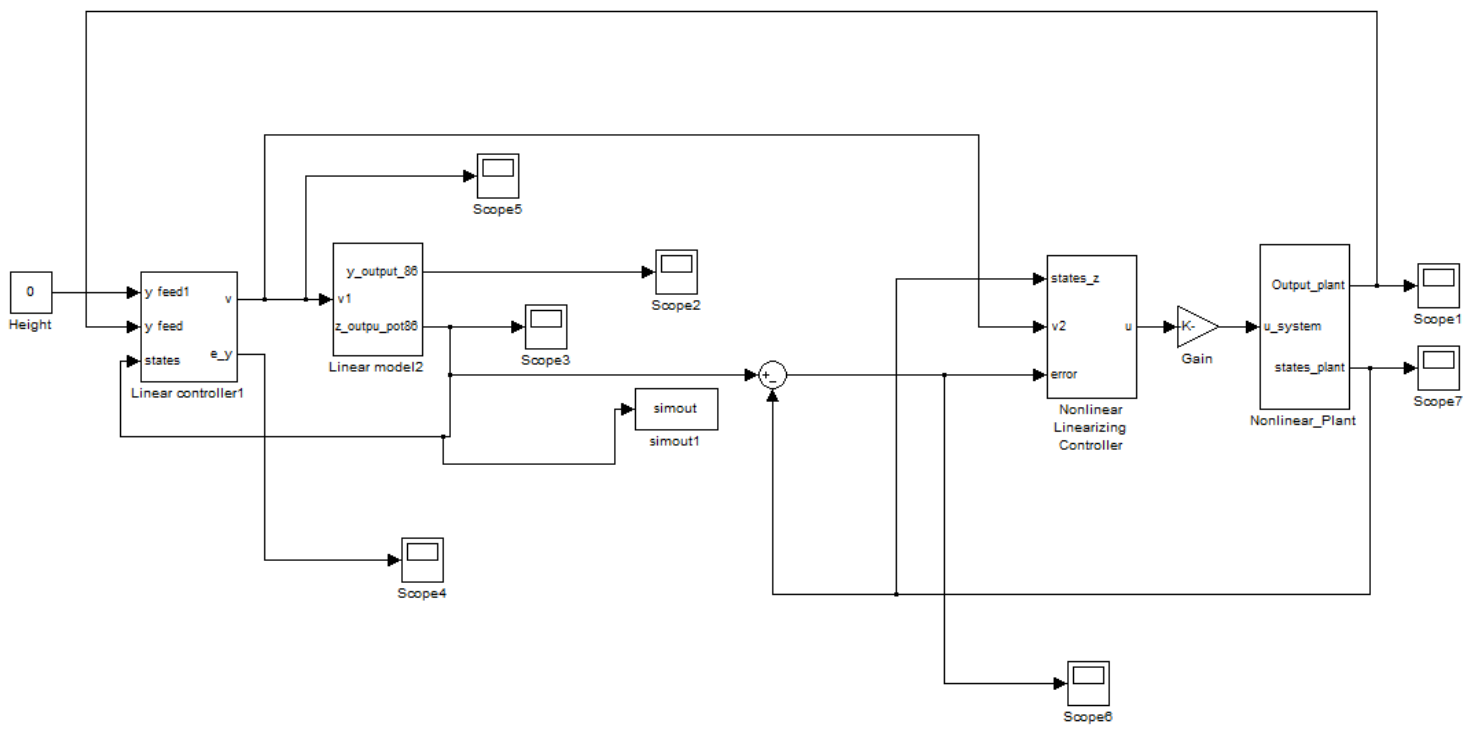

Figure 6. Simulink diagram of the Lyapunov direct method based on MRC

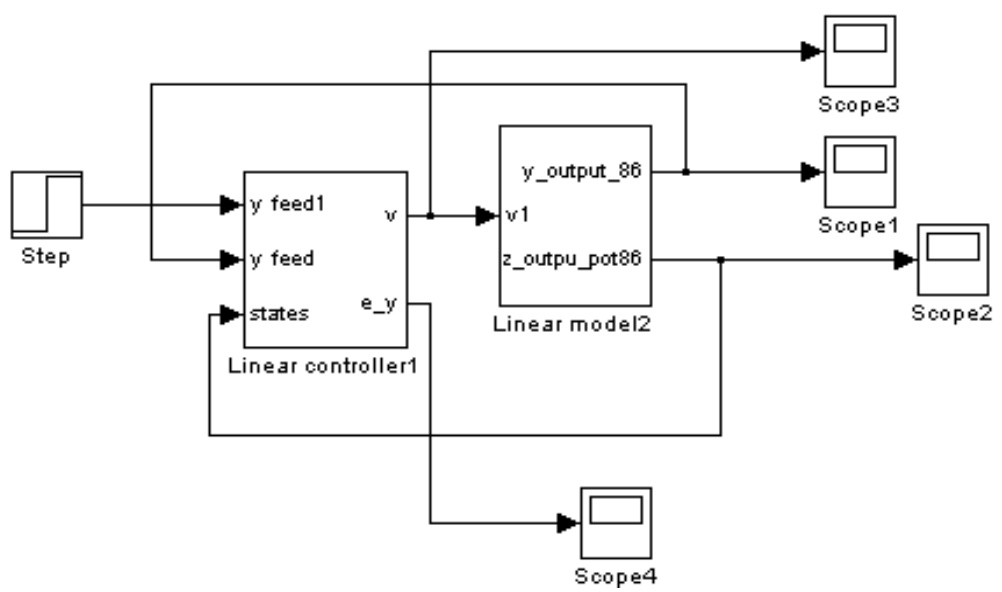

Figure 7. Simulink block diagram of the linear reference model and its controller

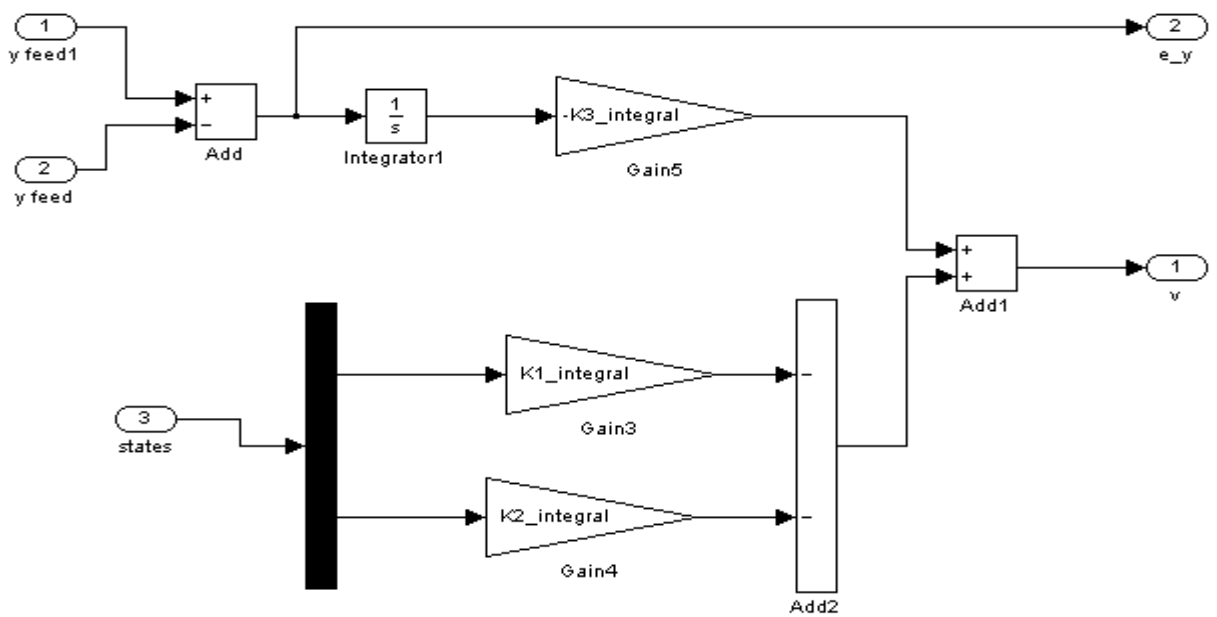

Figure 8. Simulink block diagram of the ILQR controller 


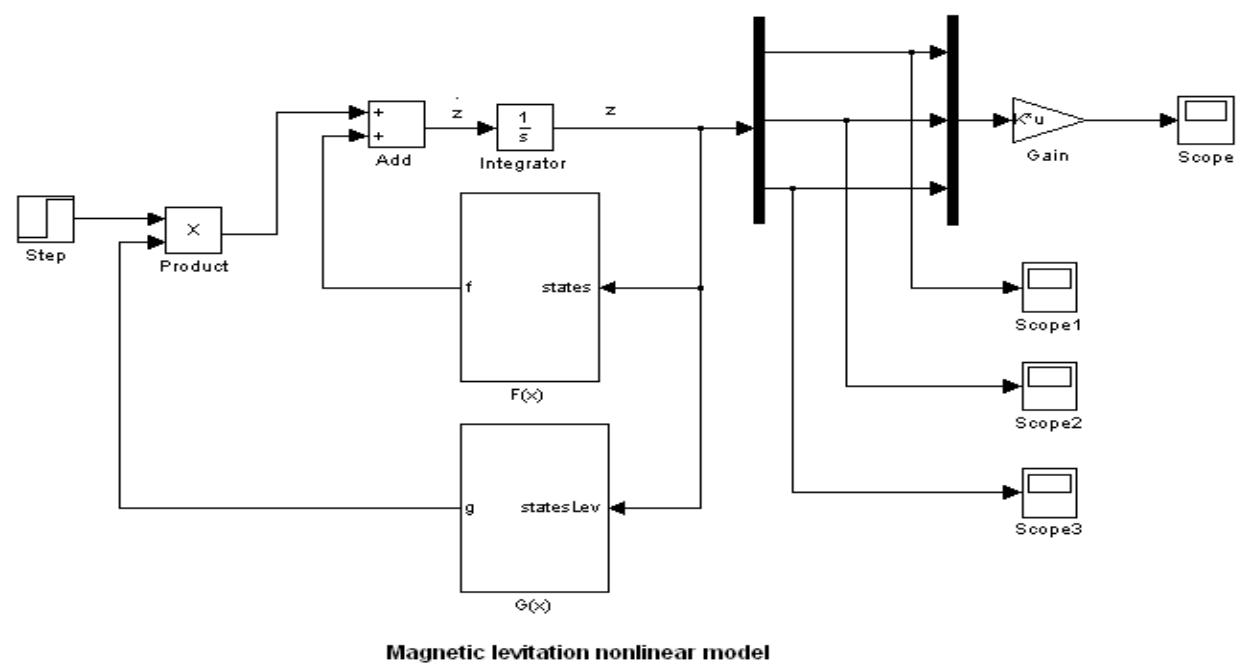

Figure 9. Magnetic levitation system nonlinear state-space model

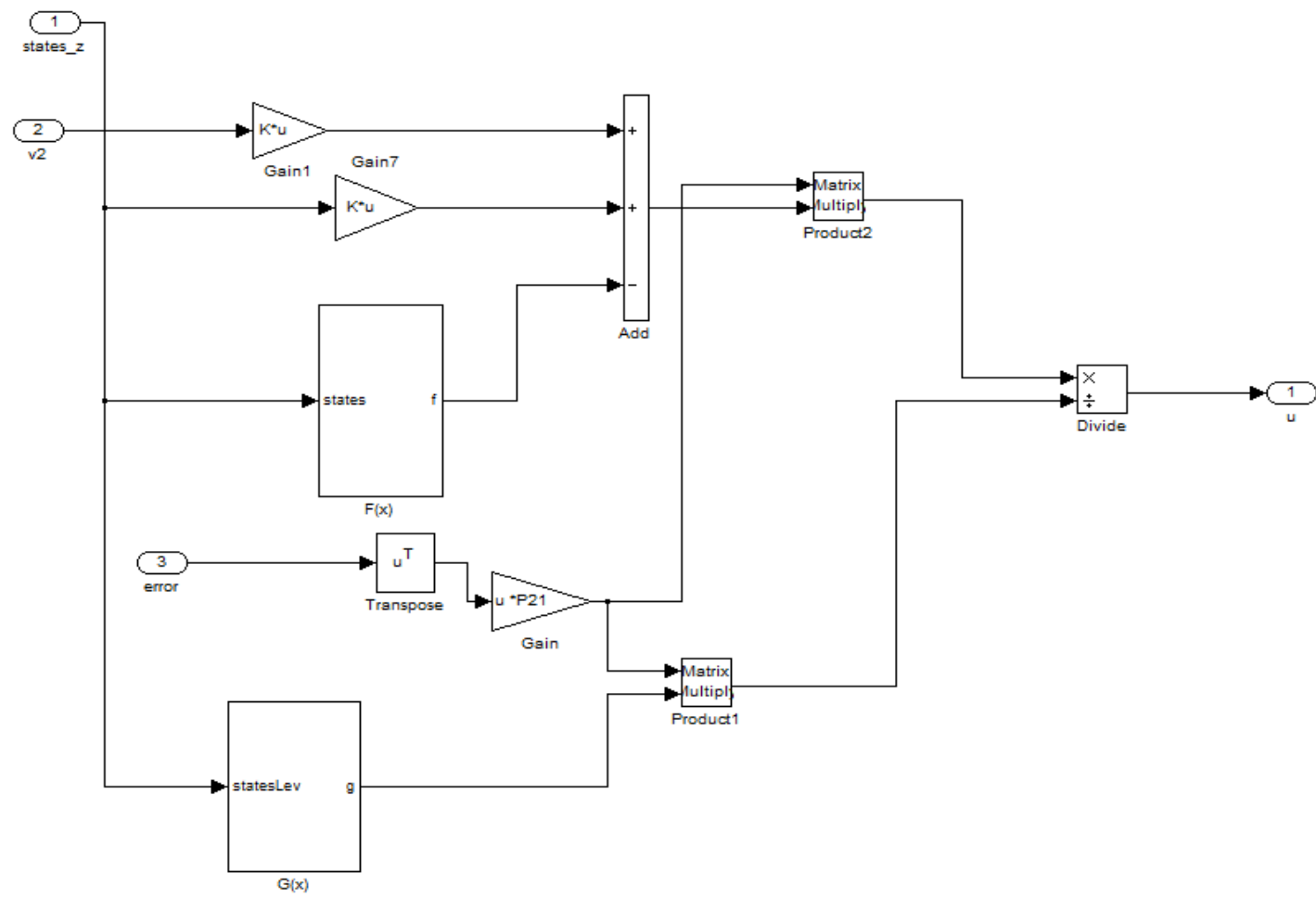

Figure 10. Simulink block diagram of the linearizing controller based on of Lyapunov second method

The reference model is formed by the combination of the linear controller and the linear plant. The nonlinear controller produces the nonlinear control signal determined in (23). The simulation results are shown in the next section.

\subsection{Simulation results}

The following results of the simulations are presented in this section:

- Linear integral controller signal

- Error signal between the set point and the output of the nonlinear magnetic levitation system

- Linearizing control signal

- Position of the ball 


\subsubsection{Scenario 1}

The initial conditions of the plant are defined as:

- Initial conditions: $\left[\begin{array}{ll}\mathbf{0} .05 & \mathbf{0}\end{array}\right]^{\prime}$.

- $\quad$ The set-point is changed to: $\boldsymbol{y}^{\boldsymbol{s p}}=\mathbf{0 . 0 1}[\mathrm{m}]$

Figure 11 presents the linear control signal when the set point is at $\mathbf{0 . 0 1}[\mathbf{m}]$. In Figure 12, the error signal between the set point and the nonlinear plant output when the set point is $\mathbf{0 . 0 1}[\mathbf{m}]$ is presented. In Figure 13, the behaviour of the nonlinear linearizing controller signal when the set point is $\mathbf{0 . 0 1}[\mathbf{m}]$ is shown, The simulation results when the set-point is $\boldsymbol{y}^{\boldsymbol{s p}}=\mathbf{0 . 0 1}[\boldsymbol{m}]$ show perfect stability of the linear and nonlinear control signals, the error signal quickly goes to zero. Additionally, there is perfect set-point tracking, no overshoot and a fast rising and settling times. The position of the ball at a set-point of $0.01[\mathrm{~m}]$ is presented in Figure 14.

\subsubsection{Scenario 2}

- The initial conditions remain the same.

- The set point is increased to: $\boldsymbol{y}^{\boldsymbol{s p}}=\mathbf{0 . 0 9}[\mathbf{m}]$

Figure 15 shows the behaviour of the linear control signal when the set-point is at $\mathbf{0 . 0 9}[\mathbf{m}]$. In Figure 16, the behaviour of the error signal between the set point and the nonlinear plant is presented when the set-point is $0.09[\mathrm{~m}]$. Figure 17 presents the nonlinear linearizing control signal when the set-point is $0.09[\mathrm{~m}]$. The position of the ball when the set-point is $0.09[\mathrm{~m}]$ is shown in Figure 18 . The simulation results when the set-point is $y^{s p}=0.09[\mathrm{~m}]$ show outstanding position control of the magnetic levitation system, closed-loop stability, very fast rising and settling time, and a small overshoot of $1 \%$.

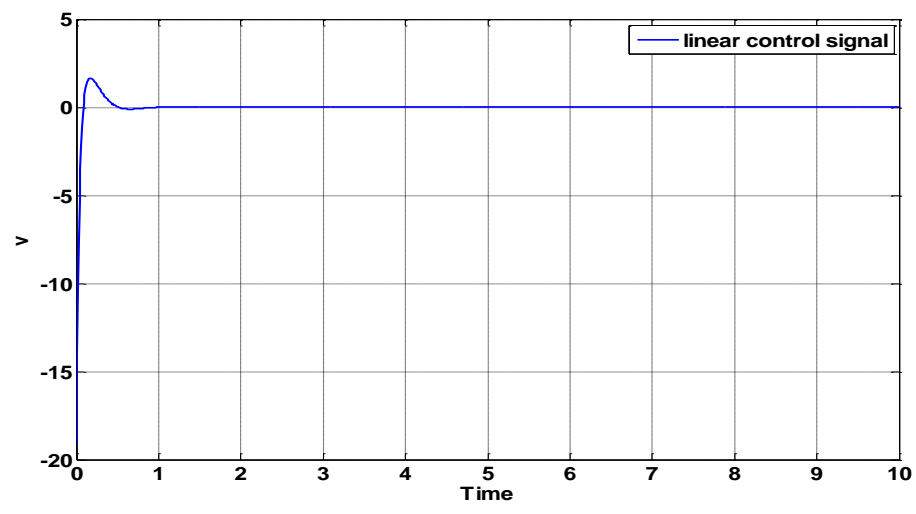

Figure 11. Linear control signal when the set point is $y^{s p}=0.01[m]$

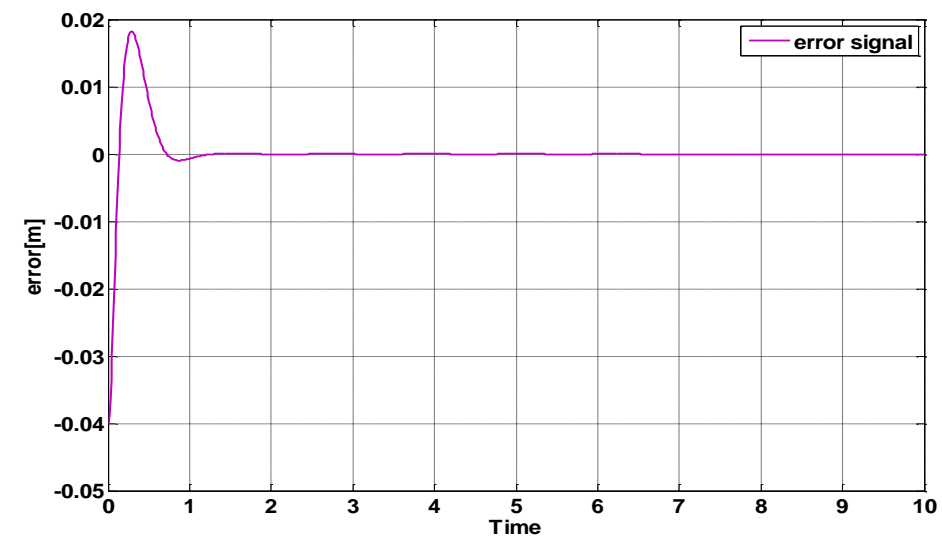

Figure 12. Error signal between the set point and the nonlinear plant output when the set point is $y^{s p}=$ $0.01[m]$ 


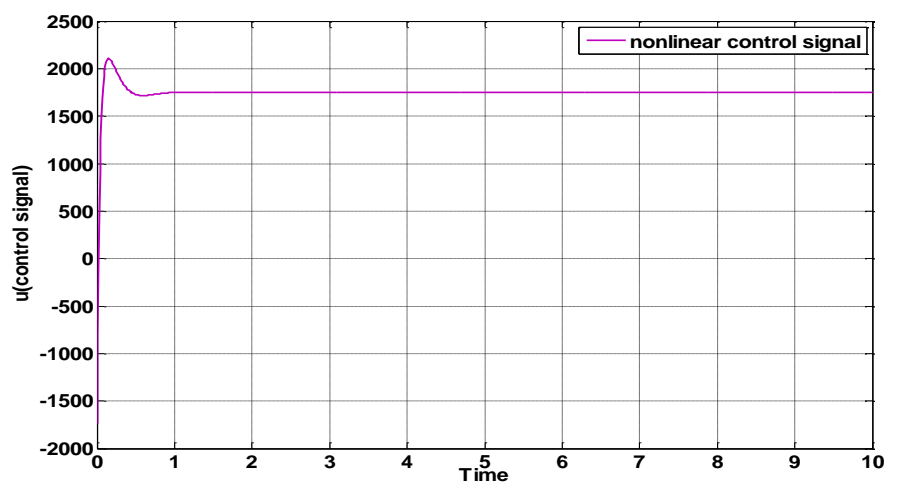

Figure 13. Nonlinear linearizing controller signal when the set point is $y^{s p}=0.01[\mathrm{~m}]$

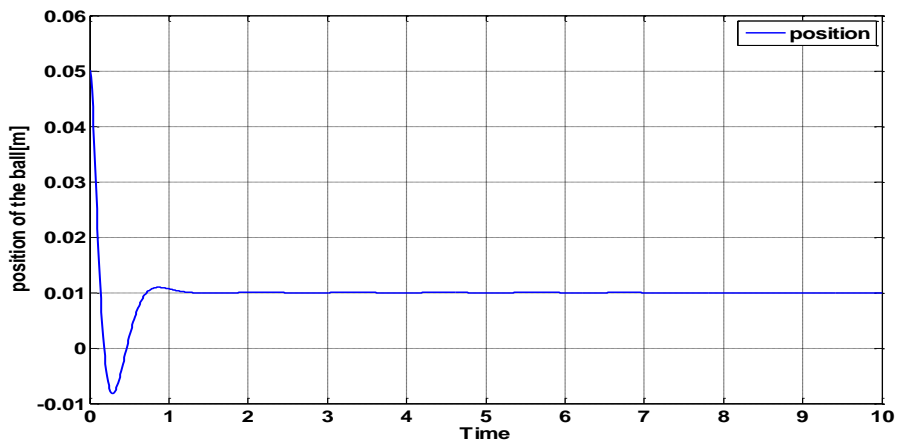

Figure 14. Position of the ball when the set point is $y^{s p}=0.01[\mathrm{~m}]$

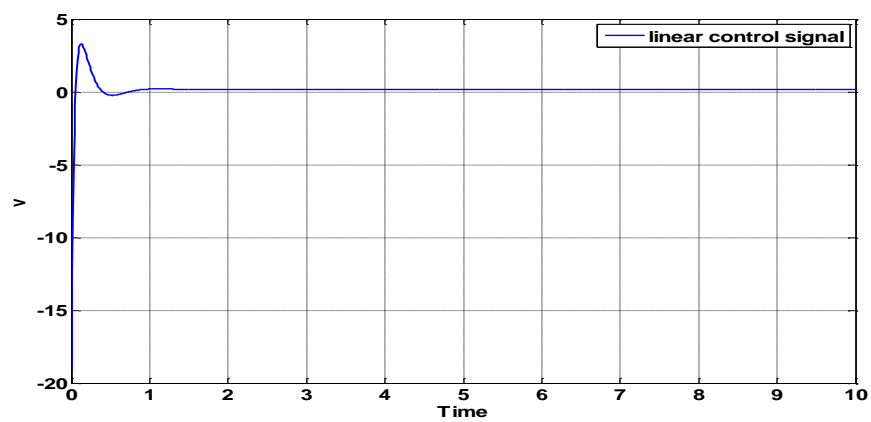

Figure 15. Linear control signal when the set point is $y^{s p}=0.09[\mathrm{~m}]$

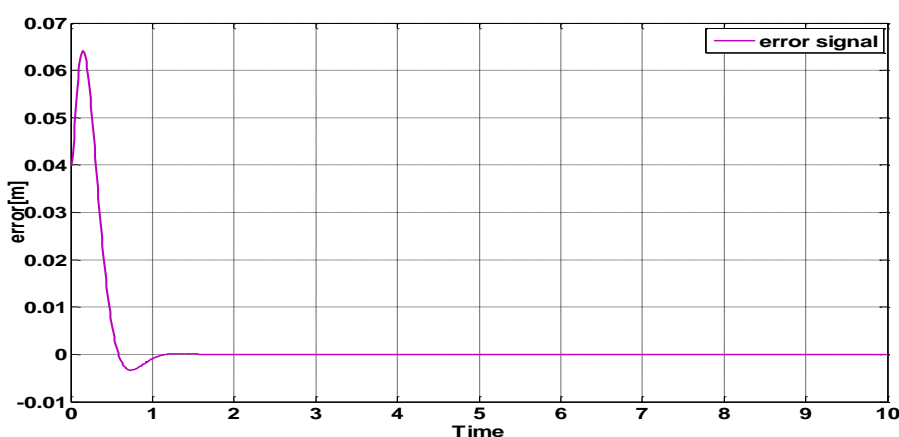

Figure 16. Error signal between the set point and the nonlinear plant output when the set point is $y^{s p}=0.09[m]$ 


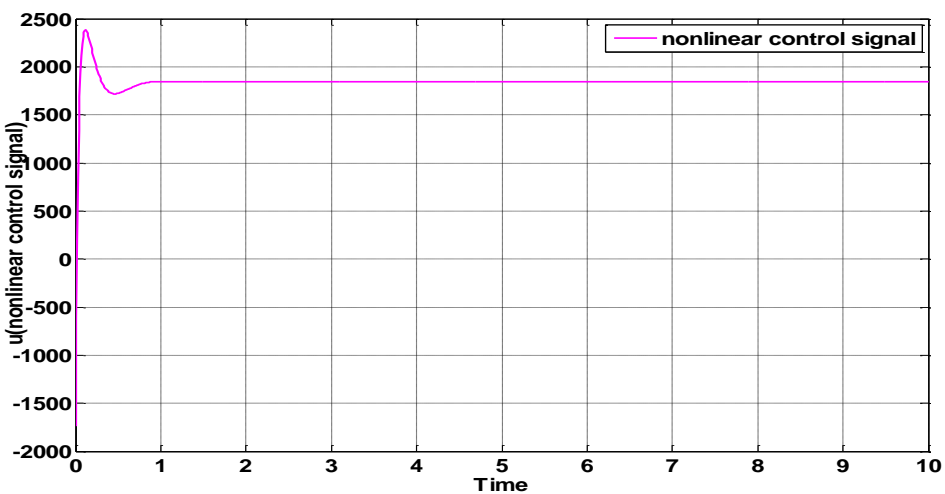

Figure 17. Nonlinear linearizing controller signal when the set point is $y^{s p}=0.09[\mathrm{~m}]$

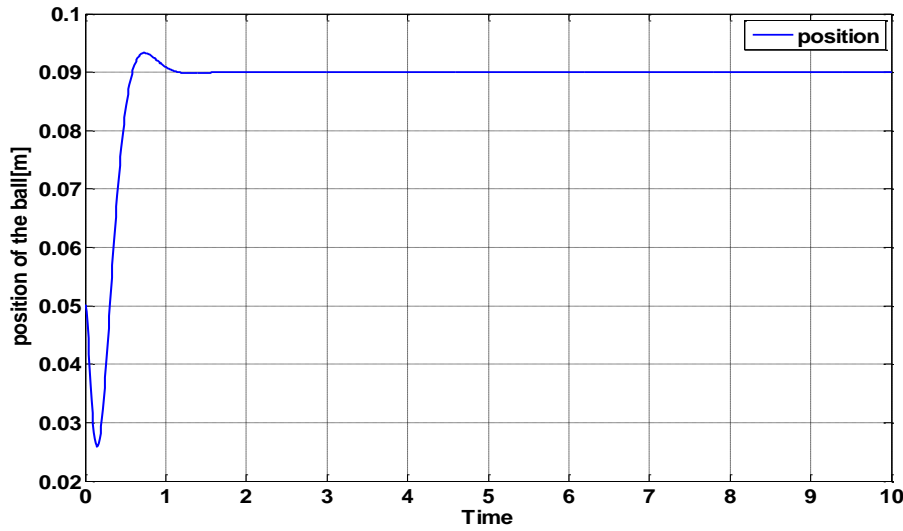

Figure 18. Position of the ball when the set point is $y^{s p}=0.09[\mathrm{~m}]$

\section{DISCUSSION OF RESULTS}

The simulation results of the magnetic levitation system show the following observations:

- The system is stable.

- The error signals go to zero.

- The plant output always follows the reference model and the set points trajectories.

- All the states of the system are stabilized.

The specifications of the dynamic output behaviour of the closed-loop system are indicated in Table 2. The time delay, percentage of overshoot, rising time, steady state error and settling time are the performance indicators analyzed.

Table 2. Simulation results comparison

\begin{tabular}{lll}
\hline Characteristics & Magnetic levitation results for the set-points \\
& $0.01 \mathrm{~m}$ & $0.09 \mathrm{~m}$ \\
\hline Time Delay & $0 \mathrm{~s}$ & $0 \mathrm{~s}$ \\
Overshoot & $0 \%$ & $1 \%$ \\
Rising Time & $0.4 \mathrm{~s}$ & $1.3 \mathrm{~s}$ \\
Steady State Error & 0.001 & 0.001 \\
Settling Time & $2.3 \mathrm{~s}$ & $1.7 \mathrm{~s}$ \\
\hline
\end{tabular}

\section{CONCLUSION}

The first contribution of this paper is the design of a new linearizing controller for a nonlinear magnetic levitation system based on Lyapunov direct method and linear model reference theory. The reference model is the combination of a linear model controlled by an ILQR. This combination stabilizes the states of the reference model to changes of the behaviour of the nonlinear model in real-time. Additionally, a new proportional control gain along with the linearizing controller is combined to provide robustness to the 
overall behaviour of the closed-loop system. The results of the simulations of the closed-loop system show excellent performance. The contribution of this paper may be extended in the following research areas in future: i) Real-time implementations of linearizing controller and integral linear quadratic regulator in LabVIEW compact RIO controller and programmable logic controllers (PLCs) for hardware-in-the-loop testing, ii) Evaluate the performance of the developed nonlinear controller in a network, where delays are affecting the closed-loop systems, and iii) The nonlinear control algorithm can be evaluated for the stabilization of systems with stochastic behaviors.

\section{ACKNOWLEDGEMENTS}

The authors thank the Centre for Substation Automation and Energy Management Systems (CSAEMS) for supporting this research.

\section{REFERENCES}

[1] F. Daldaban and N. Ustkoyuncu, "A novel linear switched reluctance motor for railway transportation systems," Energy Conversion and Management, vol. 51, no. 3, pp. 465-469, Mar. 2010, doi: 10.1016/j.enconman.2009.10.009.

[2] UIC, "High speed rail -faxt track to sustainable mobility-," UIC Passenger Department, Mar. 2012. https://uic.org/IMG/pdf/2012_high_speed_brochure_2012.pdf (accessed May 01, 2018).

[3] IEA and UIC, "Railway handbook 2017 Energy consumption and CO2 emissions focus on rail passenger services," International Energy Agency (IEA) and International Union of Railways (UIC), Nov. 2017. https://uic.org/IMG/pdf/handbook_ieauic_2017_web3.pdf (accessed Nov. 01, 2017).

[4] N. Prasad, S. Jain, and S. Gupta, "Electrical Components of Maglev Systems: Emerging Trends," Urban Rail Transit, vol. 5, no. 2, pp. 67-79, May 2019, doi: 10.1007/s40864-019-0104-1.

[5] H. Behbahani, H. Yaghoubi, and M. A. Rezvani, "Development of technical and economical models for widespread application of magnetic levitation system in public transport," International Journal of Civil Engineering, vol. 10, no. 1, pp. 13-24, 2012.

[6] C. Truesdell and W. Noll, Statistical Physics and Dynamical Systems. Berlin, Germany: Springer International Publishing, 1985.

[7] A. P. Pang, Z. He, M. H. Zhao, G. X. Wang, Q. M. Wu, and Z. T. Li, "Sum of Squares Approach for Nonlinear Hœ Control," Complexity, vol. 2018, pp. 1-7, Dec. 2018, doi: 10.1155/2018/8325609.

[8] F. Meng, A. Pang, X. Dong, C. Han, and X. Sha, "Hळ optimal performance design of an unstable plant under BODE integral constraint," Complexity, vol. 2018, pp. 1-10, Aug. 2018, doi: 10.1155/2018/4942906.

[9] H. Yaghoubi, "The most important maglev applications," Journal of Engineering (United Kingdom), vol. 2013, pp. 1-19, 2013, doi: $10.1155 / 2013 / 537986$.

[10] E. Fritz, L. Blow, J. Kluhspies, R. Kircher, and M. H. Witt, "Energy consumption of track-based high-speed trains: maglev systems in comparison with wheel-rail systems," Transportation Systems and Technology, vol. 4, no. 3 suppl. 1, pp. 134-155, Nov. 2018, doi: 10.17816/transsyst201843s1134-155.

[11] D. Wang, F. Meng, and S. Meng, "Linearization Method of Nonlinear Magnetic Levitation System," Mathematical Problems in Engineering, vol. 2020, pp. 1-5, Jun. 2020, doi: 10.1155/2020/9873651.

[12] R. Uswarman, A. I. Cahyadi, and O. Wahyunggoro, "Control of a magnetic levitation system using feedback linearization," in Proceeding - 2013 International Conference on Computer, Control, Informatics and Its Applications: "Recent Challenges in Computer, Control and Informatics”, IC3INA 2013, Nov. 2013, pp. 95-98, doi: 10.1109/IC3INA.2013.6819156.

[13] O. W. Abdulwahhab, "Design of an adaptive state feedback controller for a magnetic levitation system," International Journal of Electrical and Computer Engineering, vol. 10, no. 5, pp. 4782-4788, Oct. 2020, doi: 10.11591/ijece.v10i5.pp4782-4788.

[14] M. N. Kamarudin, S. M. Rozali, T. Sutikno, and A. R. Husain, "New robust bounded control for uncertain nonlinear system using mixed backstepping and lyapunov redesign," International Journal of Electrical and Computer Engineering (IJECE), vol. 9, no. 2, p. 1090, Apr. 2019, doi: 10.11591/ijece.v9i2.pp1090-1099.

[15] Y. D. Mfoumboulou, "Development of nonlinear control algorithms for implementation in distributed systems," 2014, Accessed: Jan. 21, 2022. [Online]. Available: http://digitalknowledge.cput.ac.za/jspui/handle/11189/2496.

[16] T. H. Wong, "Design of a Magnetic Levitation Control System - an Undergraduate Project.," IEEE Transactions on Education, vol. E-29, no. 4, pp. 196-200, Nov. 1986, doi: 10.1109/TE.1986.5570565.

[17] A. S. al-Araji, "Cognitive non-linear controller design for magnetic levitation system," Transactions of the Institute of Measurement and Control, vol. 38, no. 2, pp. 215-222, 2016, doi: 10.1177/0142331215581639.

[18] W. Zhang, J. Li, K. Zhang, and P. Cui, "Design of magnetic flux feedback controller in hybrid suspension system," Mathematical Problems in Engineering, vol. 2013, pp. 1-7, 2013, doi: 10.1155/2013/712764.

[19] M. Zhao, Q. Ge, Z. Gao, Y. Zheng, B. Zhang, and X. Cao, "Analysis of Electromagnetic and Damping Characteristics of Permanent Magnet Electrodynamic Suspension System," Electric Drive for Locomotive, vol. 2010, no. 2, pp. 1-6, 2021, doi: 10.1109/ldia49489.2021.9505871.

[20] J. Xu, Y. Du, Y. H. Chen, and H. Guo, "Adaptive robust constrained state control for non-linear maglev vehicle with guaranteed bounded airgap," IET Control Theory and Applications, vol. 12, no. 11, pp. 1573-1583, Jul. 2018, doi: 10.1049/ietcta.2017.1348.

[21] L. Zhang, Y. Zhang, C. Zhang, and H. Zhao, "Research on the Improvement of Feedback Linearization Control in Suspension System Countering Inductance Variation," Mathematical Problems in Engineering, vol. 2019, pp. 1-11, Jul. 2019, doi: $10.1155 / 2019 / 5747812$.

[22] B. Meneses-Claudio, Z. T. Santos, and A. Roman-Gonzalez, "Study and design of a magnetic levitator system," International Journal of Advanced Computer Science and Applications, vol. 10, no. 5, pp. 426-430, 2019, doi: 10.14569/ijacsa.2019.0100553.

[23] W. Zhang, J. Li, K. Zhang, and P. Cui, "Decoupling suspension controller based on magnetic flux feedback," The Scientific World Journal, vol. 2013, pp. 1-8, 2013, doi: 10.1155/2013/956790.

[24] P. Leng, Y. Li, D. Zhou, J. Li, and S. Zhou, "Decoupling Control of Maglev Train Based on Feedback Linearization," IEEE Access, vol. 7, pp. 130352-130362, 2019, doi: 10.1109/ACCESS.2019.2940053.

[25] J. Slotine and W. Li, Applied Nonlinear Control. USA: NJ, 1991. 
[26] M. Z. Ismail, M. H. N. Talib, Z. Ibrahim, J. Mat Lazi, and Z. Rasin, "Experimental simplified rule of self tuning fuzzy logicmodel reference adaptive speed controller for induction motor drive," Indonesian Journal of Electrical Engineering and Computer Science, vol. 20, no. 3, pp. 1653-1664, Dec. 2020, doi: 10.11591/ijeecs.v20.i3.pp1653-1664.

[27] Y. D. Mfoumboulou and R. Tzoneva, "Development of a Model Reference Digital Adaptive Control Algorithm for a Linearized Model of a Nonlinear Process," International Journal of Applied Engineering Research, vol. 13, no. 23, pp. 16662-16675, 2018, Accessed: Jan. 21, 2022. [Online]. Available: http://www.ripublication.com.

[28] H. R. Khoei and M. Zolfaghari, "New Model Reference Adaptive System Speed Observer for Field-Oriented Control Induction Motor Drives Using Neural Networks," Bulletin of Electrical Engineering and Informatics, vol. 5, no. 1, pp. 25-36, Mar. 2016, doi: 10.11591/eei.v5i1.520.

[29] L. H. S. Torres, L. Schnitman, C. A. V. Vasconcelos Júnior, and J. A. M. F. Felippe de Souza, "Feedback linearization and model reference adaptive control of a magnetic Levitation System," Studies in Informatics and Control, vol. 21, no. 1, pp. 67-74, Mar. 2012, doi: 10.24846/v21i1y201208.

[30] I. Al-Iedani and Z. Gajic, "Optimal control of wind turbine systems via time-scale decomposition," Energies, vol. 13, no. 2, p. 287, Jan. 2020, doi: 10.3390/en13020287.

[31] M. C. Nguyen and D. P. Vuong, "The optimal control system of the ship based on the linear quadratic regular algorithm," International Journal of Electrical and Computer Engineering, vol. 10, no. 5, pp. 4562-4568, Oct. 2020, doi: 10.11591/ijece.v10i5.pp4562-4568.

\section{BIOGRAPHIES OF AUTHORS}
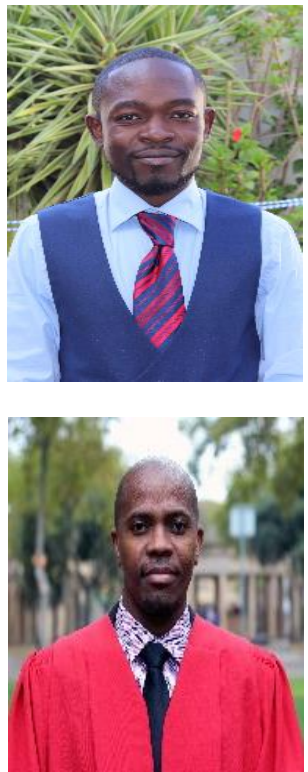

Yohan Darcy Mfoumboulou (iD \& SC P received the BTech (2011), MTech (2014) and Doctor of Engineering (2018) degrees from Cape Peninsula University of Technology (CPUT), Cape Town, South Africa. He is a Lecturer/Researcher in the Department of Electrical, Electronic and Computer Engineering (DEECE) at CPUT, where he is also member of the steering committee of the Centre for Substation Automation and Energy Management Systems (CSAEMS). From 2019 to 2021, he was a post doctorate fellow at the CSAEMS. His research interests are in the fields of Classical and Modern Control, Advanced Nonlinear Control, Real-Time Distributed Control Systems, Linear and Nonlinear Adaptive Networked Control, Digital Adaptive Control, Process Control and Instrumentation, and Smart grids. He can be contacted at email: fabolous86yo@yahoo.fr.

Mkhululi Elvis Siyanda Mnguni (D) SC P received the MTech (2013) and Doctor of Engineering (2018) degrees from Cape Peninsula University of Technology (CPUT), Cape Town, South Africa. He is a Lecturer/Researcher in the Department of Electrical, Electronic and Computer Engineering (DEECE) at CPUT, where he is also the leader of the Centre for Real-Time Distributed Systems (CRTDS). His research interests are in the fields of Power Systems stability, Substation Automation and control, Digital Substations, Protection and control, IEC 61850 standard communication, Process and Instrumentation, Adaptive protection schemes and Smart grids. He can be contacted at email: mngunim@cput.ac.za. 